\title{
PENGARUH AUDIT MANAJEMEN TERHADAP PENERAPAN PRINSIP- PRINSIP GOOD COORPORATION GOVERNANCE PADA PT. PLN (Persero) CABANG PALOPO
}

\section{DEASI OKTORASARI AZIZAH SANTOSO, MUSTAFA MUAHANI, LANTENG BUSTAMI}

\begin{abstract}
ABSTRAK
Penelitian ini bertujuan untuk melihat sejauh mana pengaruh dari audit Manajemen dalam menerapkan prinsip-prinsip Good Corporate Governance pada PT. PLN (Persero) Cabang Palopo. Di ketahui bahwa audit manajemen berkonsentrasi pada perlindungan aktiva perusahaan. Tujuan utama mereka adalah menemukan fraud manajemen (kecurangan manajemen) sebelum kecurangan tersebut dideteksi oleh pemeriksa ekstern (auditor ekstern) dan untuk mencapai "Good Corporate Governance" maka perusahaan seyogyanya mengaplikasikan prinsip-prinsip tersebut yakni Tansparan, Kemandirian, Akuntabilitas, Pertanggungjawaban, dan kewajaran.

Dalam penelitian ini penulis menggunakan Metode Analisi Regresi Sederhana untuk mengetahui pengaruh Audit Manajenen terhadap karyawan (Manajenen) itu sendiri.

Disimpulkan bahwa Audit Manajemen berpengaruh terhadap penerapan prinsip-prinsip Good Corporate Governance. Adapun pengaruh yang diberikan yakni pengaruh positif atau kontribusi positif sekitar 51\% terhadap penerapan prinsip-prinsip Good Corporate Governance di PT. PLN (Persero) Cabang Palopo
\end{abstract}

Kata Kunci: Audit Manajemen, Prinsip-Prinsip Good Coorporate Governance 


\section{Pendahuluan}

\section{Latar Belakang}

Adanya kegagalan beberapa perusahaan dan timbulnya kasus mala praktik keuangan akibat krisis tersebut adalah buruknya praktik Corporate Governance (CG). Menurut Pangestu dan Harianto (dalam Suprayitno dkk, 2004), karakteristik lemahnya praktik CG di Asia Tenggara adalah (1) adanya konsentrasi kepemilikan dan kekuatan insider shareholders (termasuk pemerintah dan pihak-pihak yang berhubungan dengan pusat kekuatan), (2) lemahnya Governance sektor keuangan, dan (3) ketidakefektifan internal rules dan tidak adanya lindungan hukum bagi pemegang saham minoritas untuk berhadapan dengan pemegang saham mayoritas dan manajer.

Contoh konkrit dari krisis itu adalah PT. PLN yang selama berdirinya dalam laporan keuangannya tidak pernah membuka laba yang merupakan hak Negara berupa Dividen yang harus di setor ke kas Negara, untuk mencapai misi PT. PLN sebagai perusahaan publik untuk memenuhi hajat hidup orang banyak sangat mendesak untuk menerapkan prinsip-prinsip Good Corporate Governance dalam standar operasionalnya.

Badan Usaha Milik Negara (BUMN) merupakan salah satu pelaku utama dalam perekonomian nasional yang telah mendukung keuangan negara dan meningkatkan kesehjahteraan masyarakat (Dolog 2004:2). Perusahaan Listrik Negara atau PLN merupakan perusahaan listrik satu-satunya yang dikelolah oleh negara untuk kepentingan rakyat pada khususnya dan merupakan sumber pendapatan negara.

Dari apa yang diungkapkan beberapa literatur, kondisi belum optimalnya perekonomian di Indonesia termasuk di dalamnya BUMN menunjukkan buruknya pelaksanaan Goog Corporate Governance. Pengaruh Good Corporate Governance terhadap kinerja organisasi telah diteliti di beberapa penelitian sebelumnya yang menunjukkan penerapan good corporate governance memiliki pengaruh pada kinerja perusahaan termasuk pada PT. PLN (Persero) Cabang Palopo. Dari fenomena dan hasil penelitian sebelumnya termasuk peneliti termotivasi untuk meneliti pengaruh penerapan prinsip-prinsip good corporate governance pada kinerja perusahaan di BUMN di Indonesia.

Masalah penelitian ini adalah Apakah Audit Manajemen berpengaruh terhadap penerapan prinsip-prinp Good Corporate Governance?. Tujuan Penelitian adalah: (a) Untuk mengetahui apakah audit manajemen dalam hal ini audit keuangan, audit operasional, dan audit kepatuhan berfungsi dalam mewujudkan good corporate governance, (b) Transparansi, kemandirian, akuntanbilitas, pertanggungjawaban, kewajaran pada PLN (persero) Cabang Palopo, (c) Sebagai masukan dan saran bagi PLN cabang Palopo untuk menciptakan Good Coreporate Governance. 


\section{Metode Penelitian}

\section{Lokasi Penelitian}

Dalam melaksanakan kegiatan penelitian ini penulis memilih objek penelitian di Kantor PT. PLN (Persero) Cabang Palopo yang berlokasi di jalan A. Kambo (Ex jalan merdeka) No. 70 Palopo.

Jenis dan sumber data

a) Data primer merupakan data yang di peroleh dari hasil observasi dan wawancara dengan pihak yang berhubungan langsung dengan proses penyusunan laporan audit manajemen di Sekretariat auditor internal PLN Cabang Palopo.

b) Data Sekunder adalah data tertulis yang diambil dari kantor PT.PLN (Persero) Cabang Palopo Sekretariat berupa data yang berisi dokumen-dokumen (Standar ISO dan Laporan audit internal) serta literatur-literatur yang berhubungan dengan masalah yang di teliti sebagai landasan teori.

Sumber Data

Data yang di perlukan mencakup data kondisi laporan hasil audit manajemen serta data-data yang mengenai Good Corporate Governance dalam hal ini di dapat di bagian SDM PLNcabang Palopo, serta diskusi langsung dari karyawan bagian akuntansi dan auditor internal, dan literatur atau referensi dari internet yang berkaitan dengan materi.

\section{Populasi dan Sampel}

Populasi dalam penelitian ini adalah bagian-bagian didalam perusahaan yang terkait dengan penerapan prinsip Good Corporate Governance dan audit manajemen yaitu pimpinan cabang 6 orang (termasuk kepala cabang dan Asisten manager) dan supervisor 14 orang dan manajemen 65 orang dan masyarakaat 15 orang (dalam hal ini di wakili mahasiswa jurusan akuntansi \& manajemen) sehingga jumlah populasi pada penelitian ini sebanyak 100 orang.

\section{Metode Pengumpulan Data}

Metode pengumpulan data yang digunakan adalah: (a) Wawancara merupakan metode pengumpulan data dengan cara bertanya langsung (berkomunikasi secara langsung) dengan pihak internal, (b) Kuisioner merupakan teknik pengumpulan data dengan cara memberi seperangkat pertanyaan atau pernyataan tertulis kepada.

\section{Metode Analisis}

Memuktikan kebenaran hipotesis yang di gunakan, maka metode analisis yang digunakan adalah metode analisis regresi sederhana. Regresi sederhana didasarkan pada hubungan fungsional ataupun kausal satu variabel independen 
dengan satu variabel dependen. (Sugioyono, 1999:204) Model persamaan regresi menurut tersebut adalah sebagai berikut :

$$
Y^{\prime} \quad: a+B x
$$

Di mana,

Y $\quad$ : Penerapan prinsip-prinsip Good Corporate Governance

$\mathrm{X}$ : Audit Manajemen

a : Harga Y bila $\mathrm{X}=0$ (Harga Konstan)

b : Angka arah atau koefisien regresi, yang menunjukkan angka peningkatan ataupun penurunan variabel dependen yang didasarkan pada variabel dependen. Bila b (+) maka naik, dan bila (-) maka terjadi penurunan.

\section{Hasil Penelitian Dan Pembahasan}

Deskripsi Hasil Penelitiaan

Sejarah Singkat Lokasi Penelitiaan

Kantor pelayanan PLN Wil. VIII sebelumnya berlokasi di jalan Pattimura samping rumah jabatan manager PLN Cabang Palopo dengan status sebagai Ranting Palopo Cabang Para-Pare, setelah di resmikan pada hari kamis pada tanggal 25 November 1993 oleh Direktur Utama PLN DR.Ir Zuhal maka PT.PLN (Persero) berubah status menjadi PT.PLN (Persero) Cabang Palopo yang sekarang berlokasi di Jalan A. Kambo (Ex Merdeka) No.70. PT. PLN (Pesero). Cabang Palopo juga membawahi 7 (tujuh) Ranting PT. PLN (Persero) yang tersebar di Luwu Raya dan Toraja, antaranya Kota Palopo, Kabupaten Belopa, Kabupaten Masamba, Kabupaten Malili, Kabupaten Tomoni, Kabupaten Makale, dan Kabupaten Rantepao

Jumlah pelanggan PT. PLN (Persero) Cabang Palopo

Berdasarkan Data pelenggan pada bulan Mei tahun 2011 total jumlah pelanggan PT.PLN (Persero) Cabang Palopo yakni 181.999 pelanggan.

Tabel : Jumlah Pelanggan PT.PLN (Persero) Se Cabang Palopo

\begin{tabular}{|l|l|l|}
\hline NO & RANTING0/UNIT & PELANGGAN \\
\hline 1 & Rtg.Sawerigading & $\mathbf{2 4 . 0 4 7}$ \\
\hline 2 & Kjg.Bua & 3.803 \\
\hline 3 & Lisdes Bastem & 152 \\
\hline 4 & Kjg.Walenrang & 6.759 \\
\hline 5 & Kjg.Lamasi & 4.626 \\
\hline & Jumlah & $\mathbf{3 9 . 3 8 7}$ \\
\hline 1 & Rtg.Belopa & $\mathbf{5 . 8 6 4}$ \\
\hline 2 & Kjg. Bajo & 3.307 \\
\hline 3 & Kjg. Suli & 3.456 \\
\hline 4 & Lisdes Larompong & 2.472 \\
\hline
\end{tabular}




\begin{tabular}{|c|c|c|}
\hline NO & RANTING0/UNIT & PELANGGAN \\
\hline 5 & Kjg. Temboe & 1.709 \\
\hline 6 & Kjg. Padang Sappa & 8.012 \\
\hline \multirow[t]{2}{*}{7} & Kjg. Noling & 1.278 \\
\hline & Jumlah & 26.098 \\
\hline 1 & Rtg. Masamba & 11.627 \\
\hline 2 & Kjg. Sabbang & 5.070 \\
\hline 3 & Kjg. Bone-Bone & 6.374 \\
\hline 4 & Kjg. Sukamaju & 6.381 \\
\hline \multirow[t]{2}{*}{5} & Kjg. Malangke & 4.770 \\
\hline & Jumlah & 34.222 \\
\hline 1 & Rtg.Malili & 3.336 \\
\hline 2 & Kjg. Tampina & 2.673 \\
\hline 3 & Kjg. Wawondulu & 2.765 \\
\hline 4 & Lisides Loeha & 619 \\
\hline 5 & Kjg. Wasuponda & 1.726 \\
\hline 6 & Kjg. Sorowako & 1.909 \\
\hline \multirow[t]{2}{*}{7} & Lisdes Solo & 654 \\
\hline & Jumlah & 13.682 \\
\hline 1 & Rtg. Tomoni & 10.555 \\
\hline \multirow[t]{2}{*}{2} & Kjg.Wotu & 5.746 \\
\hline & Jumlah & 16.301 \\
\hline 1 & Rtg. Makale & 19.678 \\
\hline 2 & Lisdes Tinoring & 5.102 \\
\hline 3 & Lisdes Ulusalu & 1.097 \\
\hline \multirow[t]{2}{*}{4} & Lisdes Bittuang & 588 \\
\hline & Jumlah & 26.465 \\
\hline 1 & Rtg. Rantepao & 23.225 \\
\hline 2 & S.Rtg.Pangala & 1.119 \\
\hline 3 & Lisdes Sesean & 818 \\
\hline \multirow[t]{3}{*}{4} & Lisdes Sapan & 682 \\
\hline & Jumlah & 25.844 \\
\hline & Total Jumlah Pelanggan & 181.999 \\
\hline
\end{tabular}

Tujuan dan Fungsi Internal yang Terkait dengan Bidang Kajian

Setiap perusahaan berlaku adanya pembagian tugas-tugas dan tanggung jawab yang harus dilakukan oleh setiap staf atau karyawan yang diberi kepercayaan kepadanya, seperti halnya yang berlaku pada PT. PLN (Persero) Cabang Palopo.

\section{Hasil Analisis Dari Penelitian}

Variabel Audit Manajemen PT. PLN (Persero) Cabang Palopo

Hasil analisis statistik deskriptif variabel Audit Manajemen dapat kita lihat pada tabel berikut ini. 
Tabel : Statistrik distribusi skor Audit Manajemen

\begin{tabular}{|l|l|}
\hline Statistik & Nilai Statistik \\
\hline Banyak Sampel & 50 \\
\hline Rata-rata & 21,08 \\
\hline Nilai tengah & 21 \\
\hline Standar deviasi & 2,174 \\
\hline Variansi & 4,728 \\
\hline Rantang skor & 10 \\
\hline Skor terendah & 15 \\
\hline Skor tertinggi & 25 \\
\hline
\end{tabular}

Variabel penerapan Prinsip-prinsip Good Corporate Governance

Hasil analisis variabel Peneraapan Prinsip-prinsip Good Corporate Governance dapat kita lihat pada tabel berikut ini.

\begin{tabular}{|l|l|}
\hline Statistik & Nilai Statistik \\
\hline Banyak Sampel & 50 \\
\hline Rata-rata & 39,88 \\
\hline Nilai tengah & 39 \\
\hline Standar deviasi & 3,998 \\
\hline Variansi & 15,985 \\
\hline Rantang skor & 21 \\
\hline Skor terenah & 29 \\
\hline Skor tertinggi & 50 \\
\hline
\end{tabular}

\section{Pembahasan Dan Hasil Penelitian}

Setelah melakukan analisis deskriptif dan analisis inferensial, hasil yang diperoleh menunjukkan bahwa hasil analisis deskriptif dari 50 sampel yang diselidiki ternyata skor rata-rata audit manajemen adalah 21,08, standar deviasi 2,174, dan variansi 4,728 dengan skor tertinggi 25 dan skor terendah 15 serta nilai tengah 21 dari skor ideal 50. Dan hasil analisi deskriptif untuk variabel penerapan prinsipprinsip Good Corporate Governance menunjukkan bahwa dari 50 sampel yang diselidiki ternyata skor rata-rata 39,88, standar deviasi 3,998, dan variansi 15,985 sedangkan nilai terendah sampel penelitian adalah 29 dan nilai tertinggi adalah 50 dari skor ideal 50.

Sedangkan hasil analisis inferensial menunjukkan bahwa dari hasil perhitungan rasio skewness dan rasio kurtosis yang dijadikan sebagai pedoman normalitas data apabila nilai yang didapatkan berada diantara -2 sampai +2 yaitu pada variabel audit manajemen mempunyai rasio skewness dan rasio kurtosis secara beurutan adalah 0,64 dan 0,35 . Hal ini menunjukkan bahwa nilai rasio skewness dan rasio kurtosis untuk variabel audit manajemen dianatara -2 sampai +2 yang artinya distribusi sampel data audit manajemen adlah normal. Untuk variabel penerapan prinsipprinsip Good Corporate Governance mempunyai rasio skewness dan rasio kurtosisnya secara berurutan adalah 0,16 dan 0,60 . Hal ini menunjukkan bahwa nilai 
rasio skewness dan rasio kurtosis untuk variabel penerapan prinsip-prinsip Good Corporate Governance diantara -2 sampai +2 yang artinya distribusi sampel data penerapan prinsip-prinsip good Corporate Governance adalah normal.

Terlihat bahwa nilai $\mathrm{t}$ hitung $>\mathrm{t}$ tabel sehingga $\mathrm{H}_{0}$ ditolak dan kolom sig (signifikan) pada tabel coefficients terdapat nilai 0,000 atau probabilitas jauh dibawah 0,05 sehingga hipotesis penelitian diterima artinya bahwa di duga audit manajemen berpengeruh terhadap penerapan prinsip-prionsip Good Corporate Governance.

$r$ square dapat disebut koefisien determiansi yang dalam hal ini berarti 0,508 atau sekitar 51\% Penerapan prinsip-prinsip Good Corporate Governance dipengaruhi atau dapat dijelaska oleh audit manajemen, sedangkan sekitar 49\% dijelaskan oleh sebab-sebab yang lain.

\section{Penutup}

Kesimpulan penelitian ini adalah bahwa Audit Manajemen berpengaruh terhadap penerapan prinsip-prinsip Good Corporate Governance. Adapun pengaruh yang diberikan yakni pengaruh positif atau kontribusi positif sekitar 51\% terhadap penerapan prinsip-prinsip Good Corporate Governance di PT. PLN (Persero) Cabang Palopo. Adapun saran dari penelitian ini adalah: (a) Hasil penelitian menunjukkan bahwa ada hubungan yang positif antara Audit Manajemen terhadap prinsip-prinsip Good Corporate Governance pada PT. PLN (Persero) Cabang Palopo, (b) Dengan hasil penelitian menunjukkan bahwa audit manajemen berpengaruh terhadap penerapan prinsip-prinsipgood corporate governance dengan persentase sekitar 51\%, (c) Diharapkan kepada pimpinan cabang PT. PLN (Persero) Cabang Palopo kiranya bijak dalam mengambil keputusan untuk meningktkan kinerja manajemen pada khususnya dan kepentingan publik pada umumnya,(d) Kepada Bapak Ketua serta dosen STIE Muhammadiyah Palopo kiranya mengadakan program khusus atau pelatihan dalam menganalisis data dalam bentuk program software SPSS versi 11.5 atau versi 14 agar memudahkan mahasiswa dalam mengelolah data dalam penelitian, (e) Dan disarankan kepada Mahasiswa-Mahasiswi STIE Muhammadiyah atau peneliti lain yang berminat melanjutkan penelitian ini, menuju skala yang lebih besar agar meneliti faktor-faktor yang mendukung erat kaitannya dengan Audit Manajemen berpengaruh terhadap penerapan prinsip-prinsip good corporate governance. 


\section{Daftar Pustaka}

_ Peraturan Menteri No. 19 Tahun 2003 Tentang maksud dan tujuan Pendirian BUMN.

_ Peraturan Menteri Negar BUMN No. 177 Tahun 2002 Tentang Praktik Good Corporate Governance Sebagai Landasan Operasionalnya.

-Metode SPSS Versi 11,5 for windows.

Anonim, Sejarah Singkt Hari Listrik Nasional PT. PLN (Persero), Palopo.

Boynton,Kell,2003,Audit Manajemen,Internet Explorer.

B.S., Lawrence,A. Dittenhofer., Mortimer,H. Scheiner., James, (2003) "Audit Internal Sawyer”, Penerbit Salemba Empat, Jakarta.

Amin Widjaja Tunggal,Ak.MBA,1995.Audit Manajemen Kontemporer, Penerbit Harvarindo, Jakarta Barat.

Dwi Ermayanti,2010,Audit Keuangan, Internet Explorer.

Indrabex.wordpress.com,Audit Manajeme,Internet Explorer.

Junaidi.,2011.Pengelola Keuangan DaerahSebuah Kajian dan Analisis Permendagri No.59 Tahun 2007 terhadap APBD Kota Palopo Tahun 2009. STIE Muhammadiyah, Palopo.

Ir.M.Iqbal Hasa,MM,2001,Pokok-pokok materi statistik 2 (statistik infrensif). Penerbit :PT Bumi Aksara,Jakarta.

I Wayan Ginastra.,2011.Warta PLN Informatif, Edukatif.PLN Wilayah Sulselrabar,Makassar.

Kep-177M-MBU.,2002.Praktek GCG pada Menteri Badan Usaha,intenet Explorer. 